quantum nature of the device could explain it.

Such breakthroughs turned Glauber into a major player in the emerging field of quantum optics, which applies established quantum theory to light. The fruits of the discipline were a better understanding of lasers and the process by which excited atoms and molecules emit photons of light. Hall and Hänsch independently used such results to build optical combs, which are laser devices that can measure the frequency of light sources with great precision.

Fields as diverse as navigation and cosmology are benefiting from optical combs, which are being used to develop a new generation of optical clocks - potentially capable of a precision of 1 part in $10^{18}$. Researchers studying the fine-structure constant, which determines the strength of the interaction between light and matter, are using the clocks to study whether the constant changes slightly with time. The devices could also lead to a redefinition of the second, and help to improve the precision of the navigation signals emitted by global positioning systems.

Jim Giles

Additional reporting by Alison Abbott

The Nobel Prize in Chemistry was announced after Naturewent to press. For coverage see

www.naturecom/news

organizations that could serve as a financial bridge for the first $\$ 55$ million.

Despite the ongoing legal and political battles, CIRM officials, grant awardees and universities are charging ahead. Even though no money is yet available, the University of Southern California in Los Angeles will soon announce plans for a large new building with a wing devoted to stem-cell research, says Francis Markland, associate dean of scientific affairs, the construction of which is to begin early next year. The university is working to recruit six to eight professors to positions there.

Elsewhere, young researchers and senior faculty members have put career decisions on hold as they consider moving to California institutes in search of CIRM research funds. "This does cause some anxiety," says physician Robert Mahley, president of the J. David Gladstone Institutes in San Francisco, which is to receive \$2.4 million in training grants over three years. "But we are prepared to wait it out." Rex Dalton

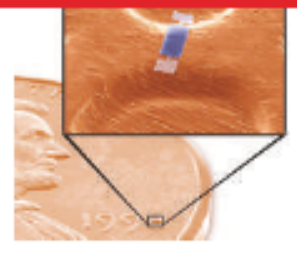

METAL DETECTORS GET SHRINIKING FEELING Tiny prototype promises better military reconnaissance. www.nature.com/nature

\title{
Gut feeling secures medical Nobel for Australian doctors
}

Barry Marshall and Robin Warren have won this year's Nobel Prize in Medicine or Physiology for discovering that most stomach ulcers are caused by the bacterium Helicobacter pylori. Despite original resistance to the findings, their work at the Royal Perth Hospital has revolutionized the treatment of gastric disease.

Plain-speaking Barry Marshall has long been a folk hero in his native Australia. But in the years after his 1982 discovery, he was dismissed as an upstart who was pushing a hypothesis that had no credibility. That pushiness, combined with dogged determination and sharp insight, kept alive the heretical idea that gastric and duodenal ulcers could be caused by a bacterial infection.

At the time, ulcers were treated with drugs that reduced acid secretion in the stomach. The drugs worked, so acidity was assumed to cause ulcers. But pathologist Warren had noticed spiral-shaped bacteria in biopsies from ulcerous stomachs, and that these were always associated with inflammation. He was convinced that the bacteria were linked to the ulcers.

He recruited a young medical intern - Marshall - to isolate and grow the bacteria in culture. The bacteria looked like Campylobacter, a newly discovered family known to cause gut infection in poultry. But Marshall's initial attempts in 1982 failed - until Easter, when culture plates were accidentally left over the four-day break. It turned out that the bacteria grow extremely slowly, and earlier attempts had simplybeen abandoned too soon. The bacteria were then shown not to be Campylobacter, but an entirely new genus, named Helicobacter.

Marshall and Warren went on to show that patients with ulcers can be treated with antibiotics. Unlike patients given acid-suppressing drugs, their ulcers do not return.

But gastroenterologists resisted the idea. Francis Mégraud, a bacteriologist at the Victor Segalen University in Bordeaux, France, remembers attending the 1988 meeting of the American Gastroenterological Association in New Orleans and hearing outraged physicians. "They seemed insulted, saying, 'we are being asked to treat stomach ulcers with antibiotics, as if it were gonorrhoea!" he says. "It was hard for them to accept that the disease could be a simple infection.

Drug companies that profited from the antiulcer drug market were also actively resistant, says Mégraud, who is secretary of the Euro- pean Helicobacter Pylori Study Group. Even some bacteriologists were suspicious - the stomach had long been assumed too acidic to host bacteria.

In frustration, Marshall did the ultimate cause-and-effect experiment. He swallowed a solution containing the bacteria, and promptly came down with an aggressive attack of the sort of gastritis that leads to ulcers. ${ }^{\alpha} \mathrm{My}$ colleagues were alarmed, and so was my wife, he recalls.

Marshall's forthright attacks on doubters did little to soften critics. Their prejudices were deepened by his youth, and the fact that Perth had no strong academic reputation. "Fortunately, I'm very thick-skinned," he says. "There was also an advantage to being isolated in Perth. I don't think I realized just how heavy the opposition was."

His untiring advocacy, and further research with Warren, subsequently repeated and extended around the world, eventually won the day. In 1991, a meeting of the Centers for Disease Control and Prevention in Atlanta, Georgia, formally declared the link between H. pylori and gastric disease.

It is now accepted that most gastric ulcers are caused by $\mathrm{H}$. pylori. The bacterium is usually acquired in childhood, being transferred through faeces or vomit between family members. It then lies dormant until adulthood. Untreated cases can lead to gastric cancer. Alison Abbott
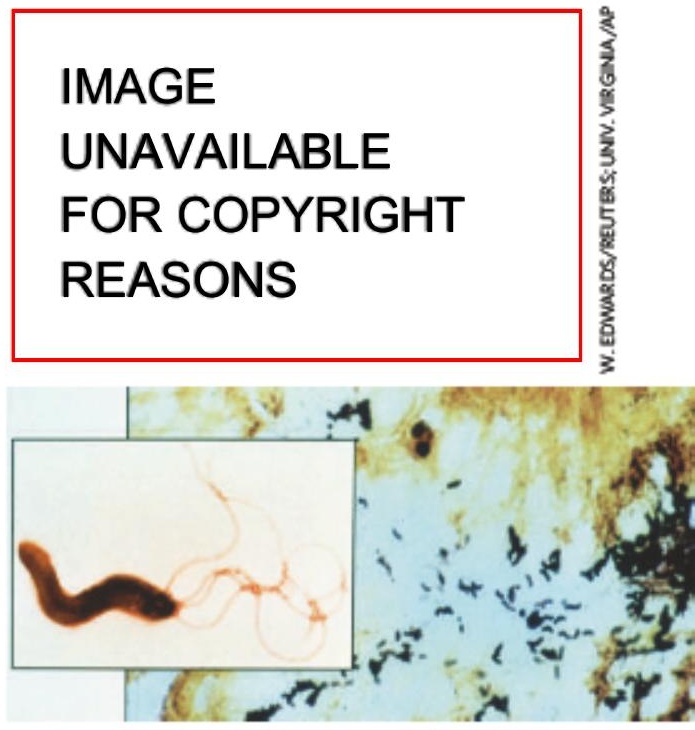

Robin Warren (left) and Barry Marshall found that Helicabacter pylori (bottom) causes stomachulcers. 